\title{
Fabrication and characterization of glass and glass-ceramic from rice husk ash as a potent material for opto-electronic applications
}

\begin{abstract}
Zinc silicate $\left(\mathrm{ZnO}-\mathrm{SiO}_{2}\right)$ glass system were fabricated using melt-quench method with zinc oxide $(\mathrm{ZnO})$ and white rice husk ash (WRHA) with compositions of $(\mathrm{ZnO})_{\mathrm{x}}(\mathrm{WRHA})_{1-\mathrm{x}}$ where $(\mathrm{x}=0.55,0.60,0.65$ and $0.70 \mathrm{wt} \%)$. Energy Dispersive $\mathrm{X}$-ray Fluorescence (EDXRF), X-ray diffraction (XRD), Fourier Transform Infrared (FTIR) spectroscopy and UV-Visible (UV-Vis) absorption spectroscopy were used to investigate the structural and optical properties of the samples. From XRD measurement, only one sample is glass and others were in crystalline form as WRHA is used to replace silica $\left(\mathrm{SiO}_{2}\right)$. This is because WRHA possess nucleating agents in its composition and this causes the samples to be highly crystalline. $\mathrm{ZnO}$ in the other hand is a highly crystalline material and encourages the formation of crystalline phase in the samples. FTIR analysis shows that the non-bridging oxygen's (NBO's) are formed as the amount of $\mathrm{ZnO}$ in the samples increases. The optical band gap shows that the optical band gap rises due to direct forbidden transition. $\mathrm{ZnO}-$ $\mathrm{SiO}_{2}$ glass system has variety of applicable characteristic because it possesses high level of chemical inertness for variety of chemical applications and it also gives various color emission which can be used in the plasma display panels (PDPs) and cathode-ray phosphor.
\end{abstract}

Keyword: Bread dough; Adaptive meshing; Extrusion pressure; Critical shear stress limit; Extrudate swell; Rheology 